\title{
Variáveis que influenciam na resistência à tração e à compressão simples de dois solos sedimentares estabilizados com cimento
}

\author{
Variables influence on splitting tensile and \\ unconfined compressive strength of two \\ sedimentary stabilized-cement soils
}

\author{
Jair de Jesús Arrieta Baldovino ${ }^{1}$, Ronaldo Luis dos Santos Izzo ${ }^{1}$, \\ Wagner Teixeira ${ }^{1}$, Mirian Dayane Pereira ${ }^{1}$
}

\footnotetext{
${ }^{1}$ Laboratório de Geotecnia ( $\left.L A B G E O\right)$ - Departamento de Construção Civil (DACOC), Universidade Tecnológica Federal do Paraná, Rua Dep. Heitor A. Furtado, 5000, CEP: 81280-340, Campus Curitiba, Sede Ecoville, Curitiba, Paraná, Brasil.

e-mail: yaderbal@hotmail.com, izzo@utfpr.edu.br, teixeira.wagner@hotmail.com,miriandayane@gmail.com
}

\section{RESUMO}

O presente artigo avalia o desenvolvimento da resistência à tração por compressão diametral ou tração indireta $\left(\mathrm{q}_{\mathrm{t}}\right)$ e da compressão simples $\left(\mathrm{q}_{\mathrm{u}}\right)$ de dois solos cimentados artificialmente sob cura de 28 dias. Para isso, dois solos siltosos (amarelo e rosa) característicos da Formação Guabirotuba de Curitiba/BR foram estabilizados com cimento de alta resistência inicial (ARI) com porcentagens de 3, 5, 7 e 9\% em referência à massa seca dos solos. Corpos de prova de $50 \mathrm{~mm}$ de diâmetro e $100 \mathrm{~mm}$ de altura (de volume $=196,35 \mathrm{~cm}^{3}$ ) foram moldados com diferentes teores de cimento $(C)$, diferentes pesos específicos secos aparentes $\left(\gamma_{\mathrm{d}}\right)$ e com uma umidade de moldagem $(\omega)$ constante em $23 \%$ e depois submetidos à ensaios de compressão simples e de tração indireta. Foi usada a relação vazios/cimento representado pela relação porosidade/teor volumétrico de cimento $\left(\eta / C_{i v}\right)$ para avaliar o desenvolvimento de $q_{u}$ e $q_{t}$ além de variáveis como $C$, porosidade $(\eta)$ e $\gamma_{d}$. Os resultados demonstram um crescimento da resistência com o aumento do teor de cimento e com a diminuição dos vazios (isto é, maior peso específico seco e menor $\eta$ ). Uma equação de dosagem para $q_{u}$ e $q_{t}$ dos solos estudados e misturados com cimento foi desenvolvida com o uso da relação $\eta / C_{i v}$ ajustada a um expoente 0,44 para fazer compatível a variação entre $\eta / C_{i v}-q_{u} \vee q_{t}$. As equações de dosagem obtiveram coeficientes de determinação acima de $94 \%$. Finalmente, se encontrou uma relação empírica de tração/compressão constante de 0,16 e de 0,14 para o solo amarelo e rosa, respectivamente.

Palavras-chave: Solo-cimento, compressão simples, tração por compressão diametral, porosidade/cimento.

\section{ABSTRACT}

This paper evaluates the development of splitting tensile strength $\left(\mathrm{q}_{\mathrm{t}}\right)$ and unconfined compressive strength $\left(\mathrm{q}_{\mathrm{u}}\right)$ of two soils artificially cemented over 28 days. For this, two silty soils (yellow and purple) characteristics of the Guabirotuba Formation of Curitiba/Brazil were stabilized with initial high strength cement with percentages of 3, 5, 7 and $9 \%$ in reference to the dry mass of the soils. Specimens with $50 \mathrm{~mm}$ diameter and $100 \mathrm{~mm}$ high (volume of 196,35 $\mathrm{cm}^{3}$ ) were molded with the different cement contents $(\mathrm{C}$ ), different molding dry unit weights $\left(\gamma_{\mathrm{d}}\right)$, and molding moisture $(\omega)$ constant at $23 \%$ and subjected to tests of unconfined compression and splitting tensile. The ratio of voids/lime represented by the porosity/volumetric cement content ratio $\left(\eta / C_{i v}\right)$ was used to evaluate the development of $q_{u}$ and $q_{t}$ in addition to variables such as $C, \eta$ and $\gamma_{d}$. The results show an increase of the mechanical resistance with the increase of the cement content and with the decrease of the voids (i.e., higher specific dry weight and lower $\eta$ ). A dosing equation for $\mathrm{q}_{\mathrm{u}}$ and $\mathrm{q}_{\mathrm{t}}$ of the soils studied and mixed with cement was developed using the $\eta / C_{i v}$ ratio adjusted to an exponent 0,44 to make $\eta / C_{i v}-q_{u} \vee q_{t}$ variation rates compatible. The dosage equations obtained coefficients of determination above $94 \%$. Finally, an empirical constant of splitting/compressive ratio of 0,16 and 0,14 for the yellow and purple soil, respectively, was found. 
Keywords: Soil-cement, unconfined compressive strength, split tensile strength, porosity/cement.

\section{INTRODUÇÃO}

A adição de matérias aglutinantes como o cimento e a cal dá ao solo um aumento significativo nas propriedades de engenharia como resistência, deformação característica e permeabilidade, atendendo aos requisitos em diversas aplicações, inclusive, para uso como material da camada de base em pavimentos e construção em solos moles. A utilização do Cimento Portland como agente de ligação se dá pelo seu alto índice de ganho de resistência durante o tempo de cura quando comparado a outras misturas e também por razões econômicas e sua disponibilidade de mercado [1, 2, 3]. A mistura solo-cimento apresenta vantagem em solos granulares, siltosos e argilas pouco plásticas e representa o tipo de estabilização mais utilizado. Em solos finos e plásticos, as forças de ligação entre as partículas são capazes de impedir a mistura com o cimento. Deste modo, a cal é eficiente quebrando estas ligações e transformando-as. Conforme descreve MOSA et al. [4], a identificação de solos moles é essencial na construção de subleitos de obras rodoviárias, uma vez que é inevitável a não utilização desse tipo de material natural, dentro das considerações técnicas, econômicas e ambientais. Deste modo, a identificação e tratamento destes solos é essencial e a adição de cal, cimento Portland, diversos produtos químicos e geomateriais como os geossintéticos têm se tornado uma solução eficaz para sua melhoria. No Brasil, a adição de cimento Portland é definida pelo Departamento Nacional de Infraestrutura de Transportes (DNIT 2006 /Brasil) como um estabilizante químico capaz de diminuir a plasticidade do solo e tornando-o menos vulnerável aos efeitos da água. Estudos em laboratório buscam achar a mínima quantidade de cimento para atingir propriedades de resistência e durabilidade. Estas estratégias resultam do fato de uma mistura solo-cimento possuir um comportamento complexo que é afetado por vários fatores, como propriedades físico-químicas do solo, quantidade de cimento, porosidade e teor de umidade durante a compactação $[5,6,7]$.

Os resultados obtidos por ONYELOWE e BUI VAN [8], apresentam a eficácia da adição variada de aditivos de cimentação ao solo além de substituir o cimento Portland comum e consequentemente reduzir a emissão de $\mathrm{CO}_{2}$. Os autores analisaram a aplicação de pó de pedra, resíduos de cerâmica triturados, cinza de palma, cimento geopolimérico à base de resíduo de madeira moída e cimento geopolimérico à base de palha de palma e constataram melhorias notáveis de cimentação com a utilização de materiais a base de cimento geopolimérico. Por outra parte, em estudos com adição de nanossílica abordam a redução do índice de plasticidade e uma melhoria na resistência de solos cimentados e que as propriedades microestruturais da pasta de cimento são melhoradas com o incremento deste material. A resistência à compressão não confinada (UCS), tem um aumento quando o teor de nanossílica atinge uma quantidade ótima de $8 \%$ e diminui quando tal teor passa para $12 \%$. Isso se dá pelo impedimento do surgimento de cristais hidróxido de cálcio. Os resultados de compressão obtidos com a adição de nanossílica apontaram que as maiores resistências (UCS) foram obtidas com maiores tempos de cura [9].

Os solos de granulometria fina, muitas vezes, apresentam problemas quando são empregados para construção de camadas de pavimentos, fundações superficiais e proteção de encostas e taludes, o que se converte em um transtorno quando, em cidades como Curitiba-Sul do Brasil, a maioria dos solos da formação geológica local (Guabirotuba) são de granulometria fina, sedimentares, expansivos, e de baixa capacidade de carga $[10,11]$. Por este motivo, a maioria dos solos dessa região não podem ser empregados para o desenvolvimento da infraestrutura física da cidade, o que é um obstáculo para os construtores e para a economia da cidade já que se deve trazer materiais de outros locais da região aumentando o orçamento das obras civis. $\mathrm{O}$ tratamento destes solos com o uso de agentes cimentantes, vem sendo uma técnica bastante empregada na engenharia geotécnica porque melhora o solo para as condições de uso mencionadas anteriormente. Recentemente BALDOVINO et al. [10] estudaram os efeitos da adição de cal hidratada (i.e. 3-9\%) em um solo siltoso da região metropolitana de Curitiba em diferentes tempos de cura. A adição de cal diminuiu a densidade seca máxima e aumentou o teor de umidade ótima, conseguindo obter resistência à compressão simples máxima de $1300 \mathrm{kPa}$ com $9 \%$ de adição de cal depois de 90 dias de cura nas condições ótimas de compactação desse teor. BALDOVINO et al. [12] calcularam os acréscimos da resistência à compressão e à tração de um solo siltoso da Formação Guabirotuba (FG) estabilizado com cal em 6 meses de cura encontrando que o valor da tração é sempre $16 \%$ do valor da compressão simples sem interessar o tempo de cura e nem a quantidade de cal adicionada. Contudo, na maioria das vezes não é possível esperar tanto tempo para liberar a utilização de obra de engenharia como na pavimentação em áreas urbanas e por isso é indispensável dispor de agentes cimentantes adicionais, como o cimento, que possam proporcionar resistências altas em menor tempo. Mesmo que a cal seja economicamente mais viável que o cimento, as vezes diminuir o tempo de ganho de uma resistência desejada pode equilibrar os custos de construção.

Apesar de numerosas aplicações, existem metodologias de dosagem baseadas em critérios racionais 
como em tecnologias de concreto, onde o fator de água/cimento tem um papel fundamental na tarefa de alcance de uma resistência específica. Recentemente, usa-se para solo-cimento a relação porosidade/volume de cimento para estudar propriedades de resistência e de durabilidade. A relação porosidade/teor volumétrico de cimento $\left(\eta / C_{i v}\right)$ é um índice entre o volume dos vazios e o volume de cimento em uma mistura com solo. A relação porosidade/cimento é um critério racional para estudar as propriedades mecânicas como compressão e tração. A relação foi introduzida na literatura por CONSOLI et al. [13] para estudar o desenvolvimento da compressão simples de misturas solo-cimento. A $\eta / C_{i v}$ também foi estendida para estudar solos estabilizados com cal $[10,12,14]$, solos reforçados com fibras de polipropileno e cimento [15], para misturas de areias com cimento [6,16] e para misturas de cinza volante com areia na presença de sal [17], dentre outros.

Para os estudos mencionados acima, $\eta / C_{i v}$ é um parâmetro adequado para prevenir e estimar propriedades como $\mathrm{q}_{\mathrm{u}}$, $\mathrm{q}_{\mathrm{t}}$ e propriedades de durabilidade (perda de massa/ciclos). Com a finalidade de proporcionar subsídios quanto ao melhoramento e estabilização dos solos da FG para uso em obras de engenharia e estender os estudos de BALDOVINO et al. [10,12]. Este estudo tem como objetivo quantificar o desenvolvimento da resistência à tração por compressão diametral $\left(\mathrm{q}_{\mathrm{t}}\right)$ e da resistência à compressão simples $\left(\mathrm{q}_{\mathrm{u}}\right)$ de dois solos siltosos provenientes da Formação, cimentados artificialmente e com cura de 28 dias, estudando os efeitos da porosidade, quantidade de cimento, peso especifico seco de moldagem e relação vazios-cimento na resistência mecânica.

\section{PROGRAMA EXPERIMENTAL}

O programa experimental foi dividido em duas etapas: a primeira foi a realização dos ensaios de caracterização dos solos e do cimento: granulometria dos solos de acordo à norma brasileira NBR 7181 [18], limites de Atterberg dos solos de acordo às normas brasileiras NBR 7180 [19] e NBR 6459 [20] , a massa especifica real dos grãos dos solos de acordo à norma ASTM D854 [21], massa especifica real dos grãos do cimento de acordo à norma brasileira NBR 16605 [22] e as propriedades de compactação dos solos nas três energias (normal, intermediária e modificada) de acordo à norma brasileira NBR 7182 [23]; e a segunda etapa, consistiu-se na moldagem, cura e rompimento dos corpos de prova solo-cimento submetidos à ensaios de compressão simples e tração por compressão diametral.

\subsection{Materiais}

Dois solos siltosos da Formação Guabirotuba (FG), cimento de alta resistência inicial (CP V) [24,25] e água destilada foram os materiais utilizados na pesquisa. As amostras de solo foram coletadas nos municípios São José dos Pinhais (solo amarelo) e Fazenda Rio Grande (solo rosa), próximos da cidade de Curitiba (Brasil), de maneira manual, em estado deformado e em quantidade suficiente para a realização de todos os ensaios. Os solos já foram utilizados em estudos anteriores por BALDOVINO et al. [10,12] para estabilização com cal hidratada. Segundo o Sistema Unificado de Classificação de Solos (SUCS), os solos são classificados como siltes arenoso de alta plasticidade $(\mathrm{MH})$.

Os resultados dos ensaios de caracterização química e física dos solos são apresentados nas Tabelas 1 e 2, respectivamente. A curva granulométrica dos solos é apresentada na Figura 1. O solo rosa apresenta uma porcentagem de areia média de 7,5\%; areia fina de 25,9\%; silte 57,6\% e de argila de 9,3\%, sendo a porcentagem de silte $(0,002 \mathrm{~mm}<\phi<0,075 \mathrm{~mm})$ composição da maior parcela do solo. O solo amarelo apresenta uma porcentagem de areia grossa de 5\%; areia média de 12\%; areia fina de 18\%; silte 60\% e de argila de 5\%, sendo a porcentagem de silte $(0,002 \mathrm{~mm}<\phi<0,075 \mathrm{~mm})$ composição da maior parcela do solo, igual ao solo rosa. Os diâmetros efetivos dos solos foram calculados como $d_{10}=0,003 \mathrm{~mm} \mathrm{e} d_{10}=0,0023 \mathrm{~mm}$ para o solo amarelo e o solo rosa, respectivamente. Adicionalmente, os diâmetros $d_{30}, d_{50}, d_{60}$ e $d_{90}$ foram medidos como $d_{30}=0,01 \mathrm{~mm}, d_{50}=0,025 \mathrm{~mm}, d_{60}=0,038 \mathrm{~mm}$ e $d_{90}=0,3$ para o silte amarelo e, $d_{30}=0,0075 \mathrm{~mm}, d_{50}=0,025 \mathrm{~mm}$, $d_{60}=0,050 \mathrm{~mm}$ e $d_{90}=0,25$ para o silte rosa. Assim, os coeficientes de uniformidade (i.e., $C_{\mathrm{u}}=d_{60} / d_{10}$ ) e de curvatura [i.e. $C_{\mathrm{c}}=\left(d_{30}\right)^{2} /\left(d_{60} \times d_{10}\right)$ ] do silte amarelo foram calculados como $C_{\mathrm{u}}=12,67$ e $C_{\mathrm{c}}=0,88$, e do solo rosa como $C_{\mathrm{u}}=21,74$ e $C_{\mathrm{c}}=0,48$. De acordo com a proposta de SKEMPTON [26] para a atividade (A) das argilas, a parcela de argila presente nos solos (Tabela 2) é classificada como ativa $(\mathrm{A}>1,25)$

O cimento foi fornecido por um fabricante local. A Tabela 1 apresenta a composição química do cimento. As propriedades químicas foram fornecidas pelo fabricante e as físicas foram calculadas no laboratório. O cimento $\mathrm{CP} V$ tem uma massa específica $\left(\mathrm{G}_{\mathrm{sc}}\right)$ de 3,11 , uma resistência axial aos 28 dias de cura de 53 $\mathrm{MPa}$, finura de $0,04 \%$ e resíduo insolúvel de $0,77 \%$. Para a realização de todos os ensaios de caracterização dos solos, das misturas solo-cimento e para a moldagem de corpos de prova, foi usada água destilada a $24 \pm 3^{\circ} \mathrm{C}$ para evitar reações não desejadas e limitar o número de variáveis no estudo. 


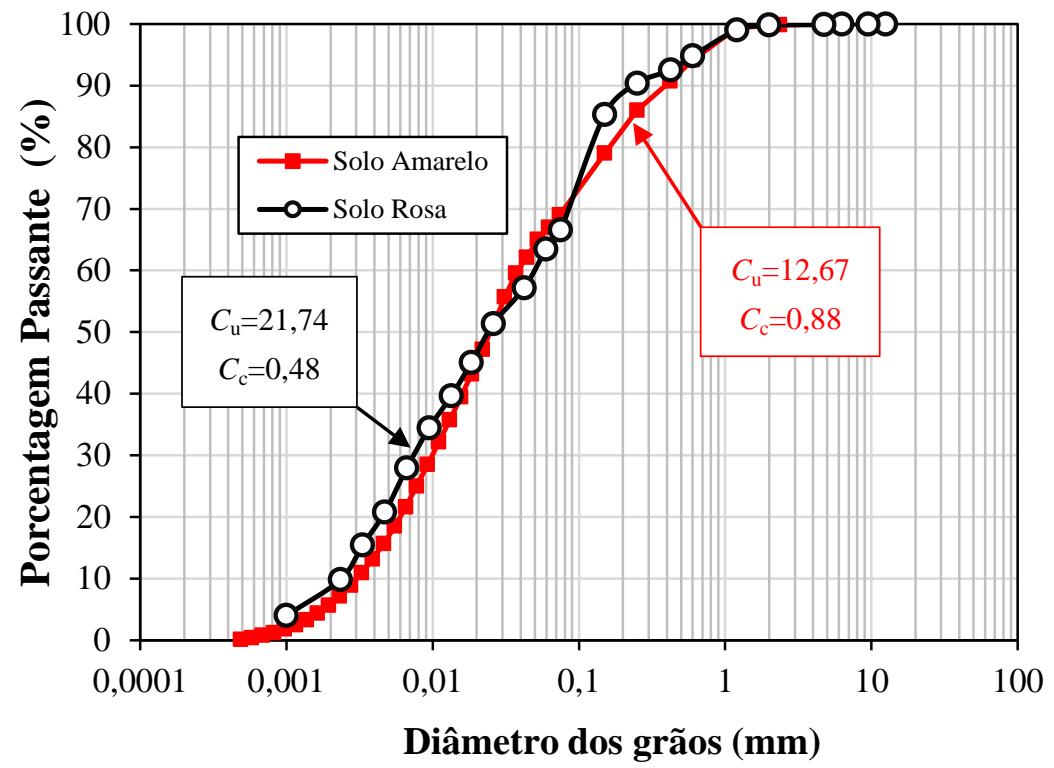

Figura 1: Curvas de distribuição granulométrica do solo amarelo e do solo rosa

Tabela 1: Composição química dos solos e do cimento

\begin{tabular}{|c|c|c|c|}
\hline \multirow{2}{*}{ COMPOSTO } & \multicolumn{3}{|c|}{ CONCENTRAÇÃO (\%) } \\
\hline & SILTE ROSA & SILTE AMARELO & CIMENTO \\
\hline $\mathrm{SiO}_{2}$ & 53,12 & 48,78 & 19,9 \\
\hline $\mathrm{Al}_{2} \mathrm{O}_{3}$ & 24,30 & 44,51 & 4,38 \\
\hline $\mathrm{Fe}_{2} \mathrm{O}_{3}$ & 10,46 & 0,61 & 2,83 \\
\hline $\mathrm{CaO}$ & 0,03 & ND & 60,73 \\
\hline $\mathrm{MgO}$ & 0,28 & ND & 4,11 \\
\hline $\mathrm{K}_{2} \mathrm{O}$ & 0,39 & 0,84 & ND \\
\hline $\mathrm{Na}_{2} \mathrm{O}$ & 0,02 & ND & ND \\
\hline $\mathrm{TiO}_{2}$ & 1,37 & 0,92 & ND \\
\hline $\mathrm{MnO}$ & 0,17 & ND & ND \\
\hline $\mathrm{P}_{2} \mathrm{O}_{5}$ & 0,22 & ND & ND \\
\hline $\mathrm{SO}_{3}$ & ND & 4,12 & 2,99 \\
\hline P. Fogo & 9,64 & 0,22 & - \\
\hline
\end{tabular}

ND: Não detectado

Tabela 2: Propriedades físicas dos solos

\begin{tabular}{lll}
\hline \multirow{2}{*}{ PROPRIEDADE } & \multicolumn{2}{c}{ VALOR } \\
\cline { 2 - 3 } & SOLO ROSA & SOLO AMARELO \\
\hline Limite de liquides (LL), \% & $53,1 \%$ & 50,82 \\
Índice de plasticidade (IP), $\%$ & $21,3 \%$ & 14,86 \\
Densidade real dos grãos (Gs) & 2,71 & 2,62 \\
Brita $(4,75 \mathrm{~mm}<\phi<19 \mathrm{~mm}), \%$ & 0 & 0 \\
Areia grossa $(2,0 \mathrm{~mm}<\phi<4,75 \mathrm{~mm}), \%$ & 0 & 5 \\
Areia média $(0,425 \mathrm{~mm}<\phi<2,0 \mathrm{~mm}), \%$ & 7,5 & 12 \\
Areia fina $(0,075 \mathrm{~mm}<\phi<0,425 \mathrm{~mm}), \%$ & 25,9 & 18 \\
Silte $(0,002 \mathrm{~mm}<\phi<0,075 \mathrm{~mm}), \%$ & 57,6 & 60 \\
Argila $(\phi<0,002 \mathrm{~mm}), \%$ & 9,3 & 5 \\
Diâmetro efetivo $\left(\mathrm{D}_{50}\right), \mathrm{mm}$ & 0,025 & 0,003 \\
$C_{\mathrm{u}}$ & 21,74 & 8,33 \\
$C_{\mathrm{c}}$ & 0,48 & 1,33 \\
Atividade, A $[\mathrm{A}=\mathrm{IP} /(\%<0,002 \mathrm{~mm})]$ & 2,29 & 2,97 \\
Classificação SUCS & MH & MH \\
Cor & Rosa & Amarelo \\
\hline
\end{tabular}




\subsection{Definição dos Pontos de moldagem}

Os pontos de moldagem foram estabelecidos após a realização dos ensaios de compactação dos solos nas três energias: normal, intermediária e modificada, de acordo com a norma brasileira NBR 7182 [23]. A Tabela 3 mostra as propriedades de compactação dos solos: peso específico seco máximo e umidade ótima de compactação nas três energias.

Tabela 3: Propriedades de compactação dos solos

\begin{tabular}{|c|c|c|c|c|c|c|}
\hline \multirow[b]{2}{*}{ SOLO } & \multicolumn{3}{|c|}{ PESO ESPECÍFICO SECO MÁXIMO (kN/m³) } & \multicolumn{3}{|c|}{ TEOR DE UMIDADE ÓTIMO (\%) } \\
\hline & $\begin{array}{l}\text { Energia } \\
\text { Normal }\end{array}$ & $\begin{array}{c}\text { Energia inter- } \\
\text { mediária }\end{array}$ & $\begin{array}{c}\text { Energia Mo- } \\
\text { dificada }\end{array}$ & $\begin{array}{l}\text { Energia } \\
\text { Normal }\end{array}$ & $\begin{array}{c}\text { Energia inter- } \\
\text { mediária }\end{array}$ & $\begin{array}{c}\text { Energia } \\
\text { Modificada }\end{array}$ \\
\hline Silte rosa & 13,80 & 15,10 & 16,15 & 28,50 & 22,80 & 20,00 \\
\hline Silte amarelo & 13,72 & 15,43 & 16,75 & 26,5 & 20,50 & 14,50 \\
\hline
\end{tabular}

Com o objetivo de estudar a influência do peso específico seco e dos vazios sobre a resistência mecânica dos solos cimentados artificialmente com o cimento mencionado, foram definidos 4 pontos de moldagem: A1, A2, A3 e A4 para o silte rosa e três pontos de moldagem: B1, B2 e B3 para o silte amarelo (Tabela 4). Estes pontos de moldagem foram definidos estrategicamente entre $16 \mathrm{kN} / \mathrm{m}^{3} \mathrm{e} 13 \mathrm{kN} / \mathrm{m}^{3}$, com uma variação do peso específico seco e com uma umidade constante de $23 \%$. Devido que em $23 \%$ de teor de umidade dá-se as maiores resistências quanto à relação porosidade/cimento, este teor foi escolhido para a moldagem das amostras solo-cimento [5]. Por outra parte, devido que o solo rosa é mais pesado que o solo amarelo, foram estabelecidos 4 pontos de moldagem para adequar melhor a variação da porosidade com os volumes de cimento adicionados, como proposto por BALDOVINO et al. [27]. Pontos de moldagem estratégicos para estudar solos melhorados já foram utilizados anteriormente por RIOS et al. [6], FESTUGATO et al. [15] e CONSOLI et al. [14]. Todos os corpos de prova solo-cimento foram submetidos à ensaios de tração e compressão simples depois de 28 dias de cura em condições de imersão para evitar ao máximo possível à influência da sucção sobre a resistência nas misturas. Devido a que em 28 dias de cura pode-se obter resistências alvas para aplicação das misturas solo-cimento em obras geotécnicas, foi escolhido como o tempo para estudar a evolução de $\mathrm{q}_{\mathrm{t}}$ e $\mathrm{q}_{\mathrm{u}}$ assim como foi realizado por BALDOVINO et al [27].

Tabela 4: Definição dos pontos de moldagem

\begin{tabular}{|c|c|c|c|c|}
\hline PONTOS DE MOLDAGEM & $\gamma_{d}\left(k N / m^{3}\right)$ & $\omega(\%)$ & $\mathrm{Sr} / \%$ & SILTE \\
\hline A1 & 15,10 & 23 & 0,77 & \multirow[t]{4}{*}{ Rosa (Solo 1) } \\
\hline A2 & 14,43 & 23 & 0,70 & \\
\hline A3 & 13,77 & 23 & 0,64 & \\
\hline A4 & 13,10 & 23 & 0,57 & \\
\hline B1 & 16,00 & 23 & 0,95 & \multirow[t]{3}{*}{ Amarelo (Solo 2) } \\
\hline B2 & 14,50 & 23 & 0,77 & \\
\hline B3 & 13,00 & 23 & 0,60 & \\
\hline
\end{tabular}

\subsection{Moldagem dos corpos de prova e ensaios de resistência mecânica}

Para os ensaios de compressão simples e tração por compressão diametral foram moldados corpos de prova de $100 \mathrm{~mm}$ de altura e $50 \mathrm{~mm}$ de diâmetro. Depois da coleta em campo, os solos foram secos, totalmente, em estufa à temperatura de $100 \pm 5^{\circ} \mathrm{C}$, destorroados e colocados em porções uniformemente distribuídas para ser misturados ao cimento. Com o intuito de maior homogeneização entre as misturas solo, ambos solos foram passantes na peneira de 4,75 mm (MESH 4) de acordo à norma ABCP ET 35 [28]. Adicionou-se a quantidade de cimento seco com referência ao peso seco da amostra de cada solo em quatro teores diferentes de adição $(3,5,7$ e $9 \%)$ de acordo a estudos prévios $[6,15,29]$. Realizou-se a mistura de cada solo com o cimento de modo que as misturas ficassem as mais homogêneas possíveis. Em seguida, foi adicionada uma porcentagem de água em peso, sendo esta porcentagem referente ao teor de umidade dos pontos de moldagem estabelecidos na Tabela $4(\omega=23 \%)$. A mistura do solo-cimento com a água destilada foi realizada em um período não superior a 5 minutos, com isto tentando minimizar as reações do cimento com a água antes do processo de moldagem dos corpos de prova. As amostras para a moldagem dos corpos de prova foram compactadas estaticamente em três camadas com um molde de aço inox com diâmetro interno de $50 \mathrm{~mm}$, altura de 100 
mm e espessura de $5 \mathrm{~mm}$, nas condições de compactação mostradas na Tabela 4. Para assegurar o peso específico seco aparente de moldagem, foi realizado o cálculo do volume do molde e do peso de mistura úmida necessários para cada corpo de prova. Após esses cálculos, foi pesada a quantidade necessária de material para cada corpo de prova. A moldagem foi feita com a ajuda de uma prensa hidráulica manual. Depois de cada processo de moldagem, três amostras da mistura eram tomadas para medir o teor de umidade em estufa durante 24 horas para assegurar o valor de $\omega=23 \%$.

Os corpos de prova foram pesados em uma balança de precisão de 0,01 $\mathrm{g}$ e as dimensões do mesmo eram medidas com o uso de um paquímetro de $0,1 \mathrm{~mm}$ de erro. Os corpos de provas extraídos do molde foram envolvidos com plástico filme transparente para manter o teor de umidade. Por último, os corpos de prova foram armazenados em câmara úmida para processo de cura durante 27 dias (a temperatura média de $24^{\circ} \mathrm{C}$ ) para prevenir mudanças significativas de umidade até o dia do ensaio. As amostras tinham que respeitar os seguintes erros máximos para serem usadas nos ensaios de compressão simples e de tração por compressão diametral: dimensões das amostras com diâmetro de $\pm 0,5 \mathrm{~mm}$ e altura de $\pm 1 \mathrm{~mm}$, peso específico aparente seco $\left(\gamma_{d}\right)$ de $\pm 1 \%$ e teor de umidade $(\omega)$ de $\pm 0,5 \%$. Os valores de $q_{u}$ e $q_{t}$ são expressos em função da porosidade inicial de moldagem $(\eta)$ para qualquer teor de cimento $(C)$ e peso especifico seco aparente de moldagem, e é calculada com a Equação [12,14]:

$$
\eta=100-100\left[\left(\frac{\gamma_{d}}{1+C / 100}\right)\left(\frac{1}{\gamma_{S S}}+\frac{C / 100}{\gamma_{S C}}\right)\right]
$$

Onde $\gamma_{S S}$ e $\gamma_{S C}$ são a massa especifica real dos grãos do solo e do cimento, respectivamente. Para cada ponto de moldagem e teor de cimento foram moldados 6 corpos de prova ( 3 para compressão e 3 para tração). Após os 27 dias de cura, os corpos de prova eram retirados da câmera úmida e logo depois imersos em um tanque com água destilada durante 24 horas antes do ensaio para garantir a sua saturação (acima de $80 \%$ ) e evitar com isto a influência da sucção na resistência como proposto por CONSOLI et al. [14,30]. Depois da imersão, eram secados superficialmente com um pano seco. Assim, todas as amostras ensaiadas foram curadas durante 28 dias.

Os procedimentos dos ensaios de compressão simples e tração por compressão diametral seguiram as normas brasileiras NBR 5739 [31] e NBR 7222 [32], respectivamente. Para a realização dos ensaios de compressão simples e tração por compressão diametral foi usada uma prensa automática Wille Geotechnik UL60 e anéis calibrados para carga axial com capacidade de $4,5 \mathrm{kN}$ e $10 \mathrm{kN}$. Os ensaios foram feitos com um sistema automatizado, medindo, principalmente, a força aplicada, com resolução de 2,5 N, a deformação, com sensibilidade de $0,001 \mathrm{~mm}$, sendo a velocidade do ensaio de $1 \mathrm{~mm} / \mathrm{min}$. A resistência a compressão simples é o valor da carga máxima de ruptura do material ou o valor da pressão correspondente à carga na qual ocorre deformação específica do corpo de prova de solo de $20 \%$, naqueles casos em que a curva tensão-deformação axial não apresenta um pico máximo. Adota-se a resistência à compressão não confinada ou simples $\left(\mathrm{q}_{\mathrm{u}}\right)$ de acordo com a seguinte expressão, quando, no ensaio a curva tensão-deformação axial, alcança um pico máximo:

$$
q_{\mathrm{u}}=\frac{\mathrm{P}_{\mathrm{R}}}{\mathrm{A}_{\mathrm{T}}}
$$

Onde $\mathrm{P}_{\mathrm{R}}$ é a carga de ruptura no pico da curva tensão-deformação axial e $\mathrm{A}_{\mathrm{T}}$ é a área transversal corrigida do corpo de prova. Adotou-se a resistência à tração por compressão diametral $\left(q_{\mathrm{t}}\right)$ de acordo com a seguinte expressão:

$$
q_{\mathrm{t}}=\frac{2 \mathrm{P}_{\mathrm{Rd}}}{\pi \mathrm{DH}}
$$

Onde $\mathrm{P}_{\mathrm{Rd}}$ é a carga de ruptura no pico da curva tensão-deformação do corpo de prova. Estipulou-se que que as resistências individuais dos corpos de prova não deveriam se afastar mais de $10 \%$ da resistência média desse conjunto como recomendado pela norma brasileira ABCP ET 35 [28]. O ensaio de tração por compressão diametral, também chamado de ensaio de tração indireta ou ensaio brasileiro, foi desenvolvido de maneira independente no Brasil e no Japão em 1943. O ensaio é realizado por meio da aplicação de uma 
carga de compressão em um corpo de prova cilíndrico que se encontra entre duas peças retangulares, com dimensões em função do diâmetro do corpo de prova, localizadas de maneira diametralmente opostas, conforme a Figura 2.

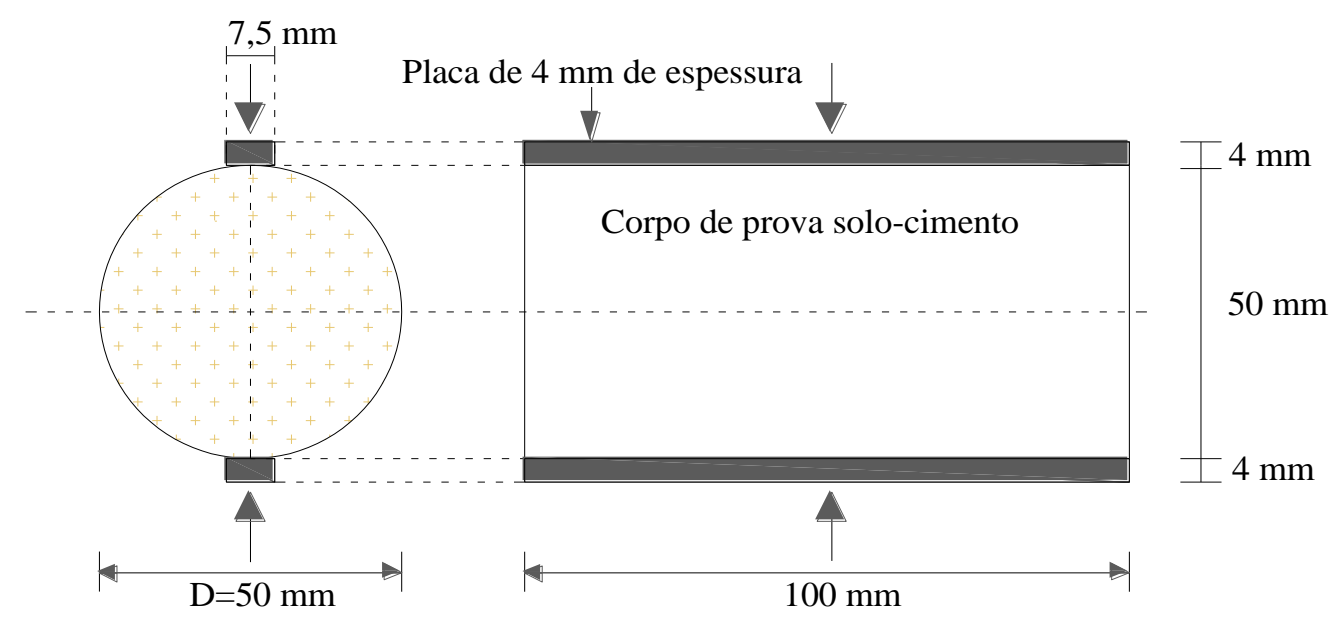

Figura 2: Corpo de prova solo-cimento submetido ao ensaio de tração por compressão diametral de acordo à norma Brasileira NBR 7222 [32]

\section{RESULTADOS E DISCUSSÕES}

\subsection{Influência do teor de cimento e peso específico seco na resistência}

Na Figura 3 se observam os resultados da resistência à compressão simples e à tração por compressão diametral dos dois siltes estabilizados com os diferentes teores de cimento. Nota-se um aumento na resistência devido ao aumento na quantidade seca de cimento adicionada na mistura para ambos solos. Por outra lado, apresenta-se um aumento da resistência com o aumento do peso específico seco aparente de moldagem (pontos de moldagem da Tabela 4). De acordo as Figuras 3a e 3c, o silte rosa obteve uma resistência à compressão máxima de $3450 \mathrm{kPa}$ e o silte amarelo obteve uma resistência máxima à compressão de $3000 \mathrm{kPa}$. A melhor maneira de representar o aumento de $\mathrm{q}_{\mathrm{u}}-\mathrm{C}$ e $\mathrm{q}_{\mathrm{t}}-\mathrm{C}$ em função de $\gamma_{\mathrm{d}}$ foi através de uma regressão linear da forma: $\mathrm{q}_{\mathrm{u}}$ ou $\mathrm{q}_{\mathrm{t}}=\mathrm{k}_{\mathrm{o}}+\mathrm{k}_{1} \mathrm{C}$ (onde $\mathrm{k}_{\mathrm{o}}$ e $\mathrm{k}_{1}$ são constantes que dependem da regressão por mínimos quadrados). Em referência à resistência à tração, foi maior no solo amarelo comparado com o solo rosa. $\mathrm{O}$ máximo valor de $\mathrm{q}_{\mathrm{t}}$ obtido no solo rosa foi de $550 \mathrm{kPa}$ e no solo amarelo de $500 \mathrm{kPa}$.

A resistência à compressão simples $\left(\mathrm{q}_{\mathrm{u}}\right)$ é a propriedade mais amplamente referenciada do solocimento. $\mathrm{O} \mathrm{q}_{\mathrm{u}}$ serve de critério para determinar os requisitos mínimos de cimento a ser adicionado para estabilizar quimicamente um solo. Um dos requisitos é descrito pelo Texas Department of Transportation (TxDOT). Objetivando a estabilização do solo, a quantidade necessária de adição de cimento baseia-se principalmente em atingir uma resistência mínima após o condicionamento da umidade no laboratório. Conforme determinado pelo último TxDOT Pavement Design Guide de 2013 [33], a resistência de compressão simples alvo não confinada para bases estabilizadas de cimento é de cerca de 300 Psi (ou $2100 \mathrm{kPa}$ ) e para sub-base o valor diminui para $1200 \mathrm{kPa}$. No Brasil, segundo a manual do Departamento Nacional de Infraestrutura de Transportes (DNIT) 143 [34] a resistência alvo é também de $2100 \mathrm{kPa}$. Tendo como referência o TxDOT e o DNIT, as misturas solo-cimento que alcançaram a resistência alvo foram: Solo rosa com $7 \%$ de cimento (pontos A1 e A2) e 9\% (pontos A2, A2 e A3) e solo amarelo com 7\% (ponto B1) e 9\% (pontos B1 e B2). Em outra análise, grande parte das misturas alcançaram resistências de projeto para construção de sub-base (acima de $1200 \mathrm{kPa}$ ). Para o solo rosa, a maioria das misturas cumprem com o requerimento, exceto as compactadas com 3\% e 5\% de cimento no ponto A4. Para o solo amarelo, $60 \%$ das misturas podem ser utilizadas, a exceção são as compactadas no ponto B3 e as compactadas com 3\% de cimento. Assim, 5\% (compactando acima de $14 \mathrm{kN} / \mathrm{m}^{3}$ ) constitui o teor mínimo requerido para usar essas misturas na construção de sub-bases. 

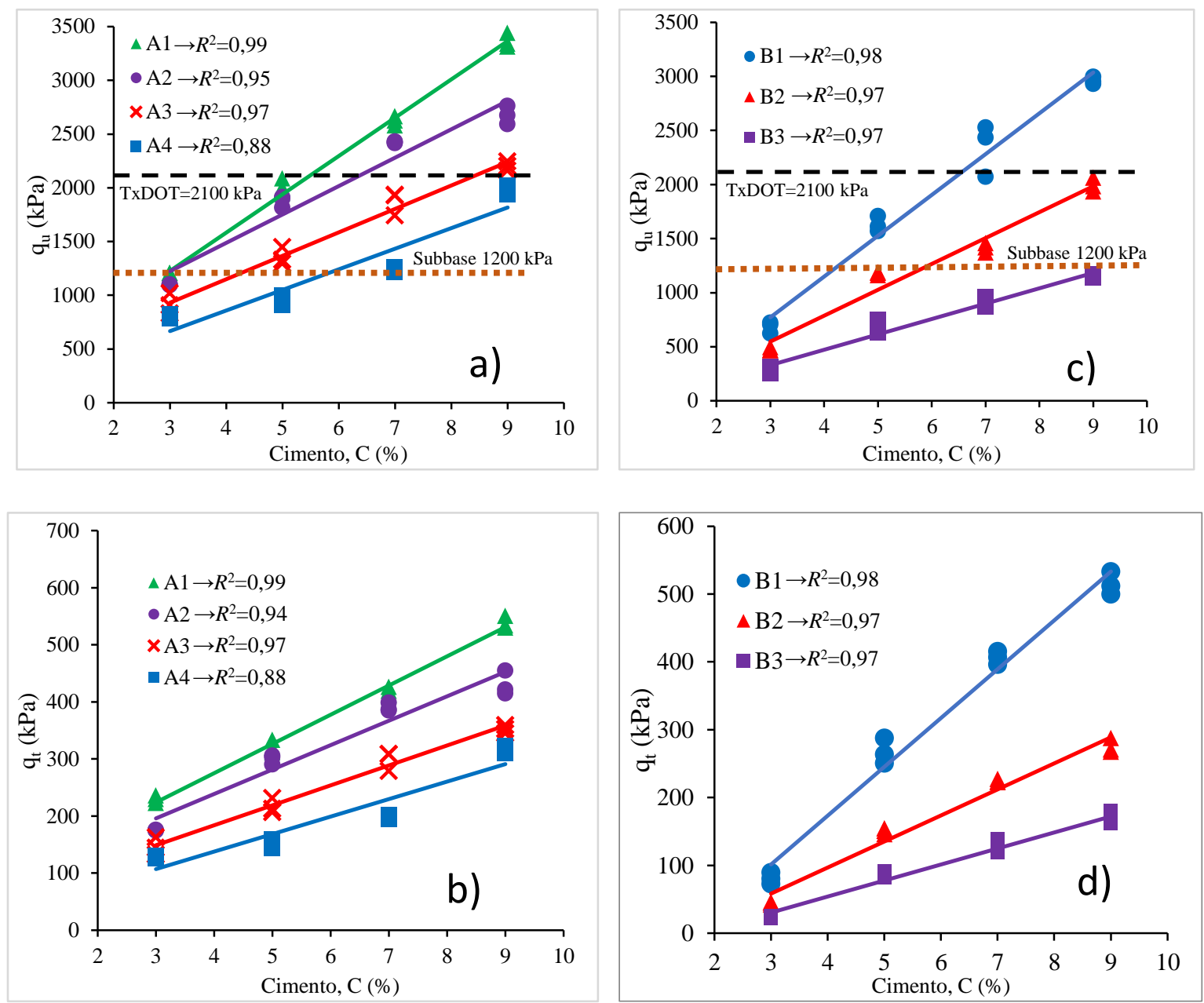

Figura 3: Influência do teor de cimento na resistência à tração por compressão diametral $\left(\mathrm{q}_{\mathrm{t}}\right)$ e à compressão simples $\left(\mathrm{q}_{\mathrm{u}}\right)$. a) Compressão simples solo rosa b) Tração solo amarelo c) Compressão solo rosa d) Tração solo amarelo.

A Figura 4 mostra a variação do grau de saturação final das amostras de solo-cimento após o período de imersão por 24 horas. 11\% das amostras de silte amarelo que foram moldadas com $95 \%$ de saturação (ver Tabela 4) lograram maiores valores de saturação. No entanto, todas as amostras conseguiram atingir como mínimo $80 \%$ de saturação e aquelas moldadas em um baixo grau de saturação absorveram maior volume de água durante o processo de imersão devido à alta sucção matricial nas fazes sólido-ar. De acordo a CONSOLI et al. [14], acima de $80 \%$ de saturação, a sucção não tem interferência nos valores finais de resistências das misturas. Assim, todas as amostras foram alvas para a realização dos ensaios de compressão e tração indireta. 


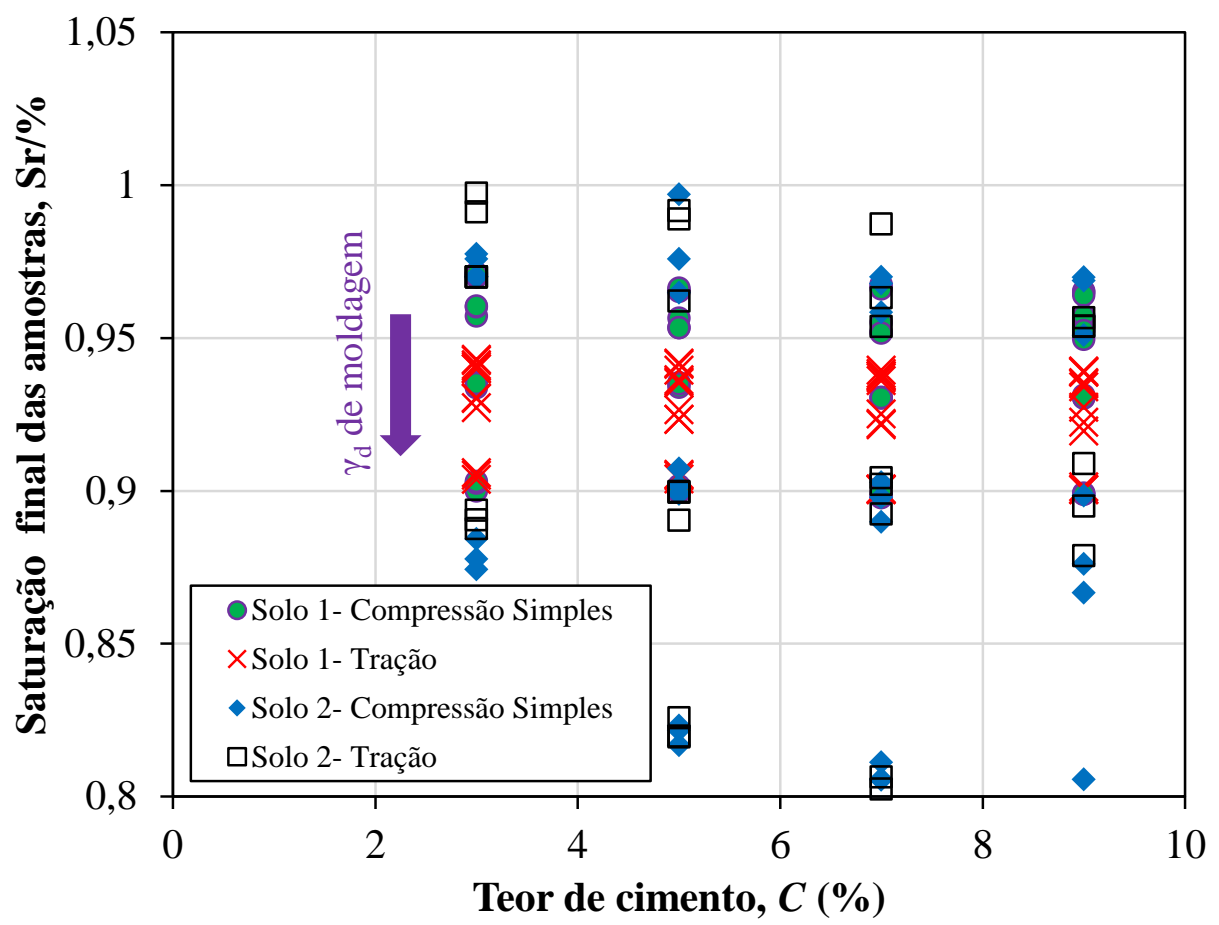

Figura 4: Grau de Saturação final das amostras após imersão durante 24 horas

\subsection{Influência dos vazios na resistência à compressão e à tração}

A Figura 5 apresenta os resultados da resistência mecânica dos dois solos influenciados pela porosidade inicial de moldagem $(\eta)$. A porosidade das misturas define-se como o volume de vazios que estão presentes em um corpo de prova solo-cimento de volume definido (V) de $196,35 \mathrm{~cm}^{3}$, sendo os vazios o volume de água e o volume de ar. A porosidade pode ser calculada aplicando a Equação (1). Devido ao aumento no peso específico seco aparente de moldagem das amostras (para o solo amarelo e rosa) definido na Tabela 4, a quantidade de material (solo+água+cimento) úmido a inserir no volume $\mathrm{V}$ é maior porque a quantidade de vazios a preencher diminui. Isso também se reflete nos resultados de resistência mecânica, quanto menor o volume de vazios e maior a quantidade de cimento, maior é a resistência $\mathrm{q}_{\mathrm{u}}$ e $\mathrm{q}_{\mathrm{t}}$ para os dois solos, como pode ser observado na Figuras 5(a)-5(d).

As Figuras 5(a)-5(d) também apresentam que a variação da resistência $\mathrm{q}_{\mathrm{u}}$ e $\mathrm{q}_{\mathrm{t}}$ com a porosidade se dá de maneira linear. Em média, para o solo rosa [Figuras 5(a) e 5(b)], a redução de 5\% no valor da porosidade significa um aumento de 800 e $170 \mathrm{kPa}$ na compressão simples e na tração, respectivamente. Para o solo amarelo [Figuras 5(c) e 5(d)], uma redução de 5\% na porosidade produz um aumento de 1250 e $220 \mathrm{kPa}$ na compressão e na tração, respectivamente. Nota-se um aumento mais significativo na resistência e na diminuição dos vazios no solo rosa em referência ao solo amarelo. O aumento da resistência com a diminuição da porosidade foi reportado anteriormente para misturas solo-cimento, solo-cal, solo-cal-cinza volante [35].

Para LI e AUBERTIN [36] existe uma relação direta entre $q_{\mathrm{u}}-\eta$ e $\mathrm{q}_{\mathrm{t}}-\eta$ para vários materiais como solos, rochas, cerâmicas, metais e concretos. A diminuição da porosidade proporciona uma maior capacidade de distribuição de tensões no interior dos corpos de prova solo-cimento, de mesmo modo que a maior capacidade de mobilização do atrito nas porosidades mais baixas também contribui para o ganho de resistência à tração do material. Assim, independentemente da quantidade de cimento utilizada, a redução na porosidade do material promove ganhos consideráveis de resistência à tração por compressão diametral e na compressão simples. 

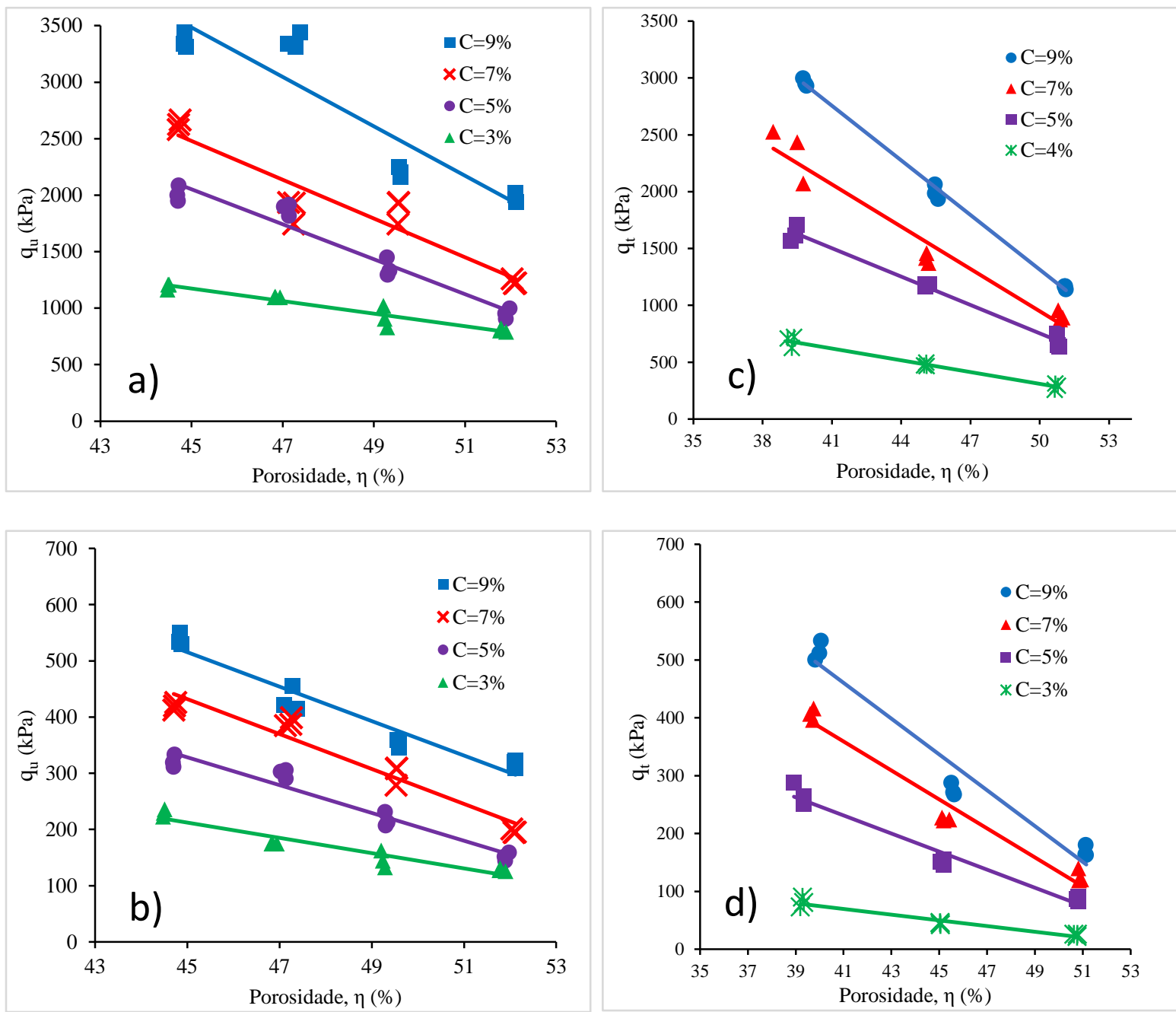

Figura 5: Influência do teor de cimento na resistência à tração por compressão diametral $\left(\mathrm{q}_{t}\right)$ e à compressão simples $\left(\mathrm{q}_{\mathrm{u}}\right)$. a) Compressão simples solo rosa b) Tração solo rosa c) Compressão solo amarelo d) Tração solo amarelo.

\subsection{Influência da porosidade e do volume de cimento na resistência à compressão e à tração}

A relação porosidade/teor volumétrico de cimento $\left(\eta / C_{i v}\right)$ foi utilizada para estudar a evolução da resistência à compressão simples e à tração por compressão diametral. A relação $\eta / C_{i v}$ é definida em relação a porosidade da mistura solo-cimento e do volume de cimento utilizado na mistura nas condições iniciais de moldagem, definidos previamente na Tabela 4. Calcula-se a porosidade como uma condição inicial da matriz solocimento em um peso específico seco $\left(\gamma_{\mathrm{d}}\right)$, pré-estabelecido e um teor de umidade desejado. Desta forma, a resistência mecânica da matriz solo-cimento pode dar-se como uma relação direta da porosidade dos corpos de prova, tal como, uma função do inverso do teor volumétrico de cimento $\left(1 / \mathrm{C}_{\mathrm{iv}}\right)$, conforme foi demostrado em estudos anteriores [35,37]. Para encontrar uma relação direta e compatível entre $\eta$ e $C_{i v}$, como uma razão matemática e, converter as duas variáveis em uma dependência para $\mathrm{q}_{\mathrm{u}}$ e $\mathrm{q}_{\mathrm{t}}$, o valor de $\mathrm{C}_{\mathrm{iv}}$ deve se ajustar em um expoente $\mathrm{B}$ que melhor se adeque aos resultados obtidos de resistência, o valor de $\mathrm{B}$ encontra-se entre 0,01 e 1,00 com variações de 0,01 , tal como é feito na literatura atual [5,15,16]. Desta maneira, o melhor valor calculado para $B$ que se ajusta aos valores de $q_{u}$ e $q_{t}$ dos corpos de prova do programa experimental foi o de 0,44 (Ver Figuras 6-7).

O valor de 0,44 significa que a influência da porosidade $(\eta)$ na mistura solo-cimento exerce maior atuação na resistência $q_{u}$ e à tração indireta $q_{t}$ do que o teor volumétrico de cimento. De tal forma que, um aumento na porosidade necessita de um incremento proporcionalmente maior no teor de cimento para compensar o aumento dos vazios devido à falta de compactação e manter a resistência constante. Valores para B próximos a 1,00 são mais encontrados para solos granulares onde os parâmetros $\eta$ e $\mathrm{C}_{\mathrm{iv}}$ exercem a mesma influência sobre $q_{u}$ e $q_{t}$, onde as variações proporcionais nos valores de $\eta$ e $C_{i v}$ mantêm constantes os valores de $\mathrm{q}_{\mathrm{u}}$ e $\mathrm{q}_{\mathrm{t}}$ [38], ou seja, para assegurar uma alta resistência para misturas de cimento com solos granulares, tanto 
os vazios como o volume do cimento são a chave para alcançar um determinado valor para $\mathrm{q}_{\mathrm{u}} \mathrm{e} \mathrm{q}_{\mathrm{t}}$. No entanto, para misturas de cimento com solos de granulometria fina (siltes e argilas) a chave para alcançar uma alta resistência encontra-se em aplicar uma alta energia de compactação ou aumentar de maneira significativa a quantidade de cimento.

Na Figura 6 se apresenta a variação da resistência à compressão simples e da tração do silte rosa com o índice $\eta / C_{i v}$ ajustado a um expoente de 0,44 . De igual maneira a Figura 7 apresenta os resultados da resistência $q_{u}$ e $q_{t}$ das misturas de cimento com o solo amarelo. Nota-se nas Figuras 6-7 que o parâmetro $\eta / C_{i v}$ é adequado para estabelecer o crescimento da resistência mecânica das misturas para ambos solos em todas as condições de moldagem (Tabela 4). Dá-se o crescimento da resistência da forma potencial: $\mathrm{q}_{\mathrm{u}}$ ou $\mathrm{q}_{\mathrm{t}}=\mathrm{k}_{2} \times$ $\left[\eta / \mathrm{C}_{\mathrm{iv}}{ }^{0,44}\right]^{-\mathrm{B}}$ (onde $\mathrm{k}_{2}$ e B são constantes que dependem de múltiplas fatores: teor de umidade, tipo de solo, tipo de agente cimentante e tempo de cura $[12,14]$. Assim, com a finalidade de comparar a relação $q_{u}-k_{2}\left[\eta / C_{i v}{ }^{0,44}\right]^{-}$ ${ }^{\mathrm{B}}$ e $\mathrm{q}_{\mathrm{t}}-\mathrm{k}_{2} \times\left[\eta / \mathrm{C}_{\mathrm{iv}}{ }^{0,44}\right]^{-\mathrm{B}}$, na Figura 8 se apresenta o crescimento da resistência dos dois siltes em paralelo, mostra que o solo rosa obtém maiores resistências tanto na compressão simples como na tração indireta quando comparado com o solo amarelo. Essa superioridade se dá principalmente pela composição química do solo e distribuição do tamanho das partículas (i.e., $C_{\mathrm{c}}$ e $C_{\mathrm{u}}$ ), como demonstrado em estudos prévios [38]. A reação entre a cal $\left[\mathrm{Ca}(\mathrm{OH})_{2}\right]$ gerada na hidratação do cimento e os argilo-minerais do solo formam silicatos de cálcio hidratos (CSH) que são os agentes cimentantes responsáveis pelo ganho de resistência. Os silicatos de cálcio ligam-se às partículas de solo, conferindo maior resistência à mistura. Ao solo rosa ter maior porcentagem de sílica (ver Tabela 1) e maior valor no $C_{\mathrm{u}}$ (i.e., aumento do intervalo de variação dos diâmetros) possibilita maior desenvolvimento da resistência.

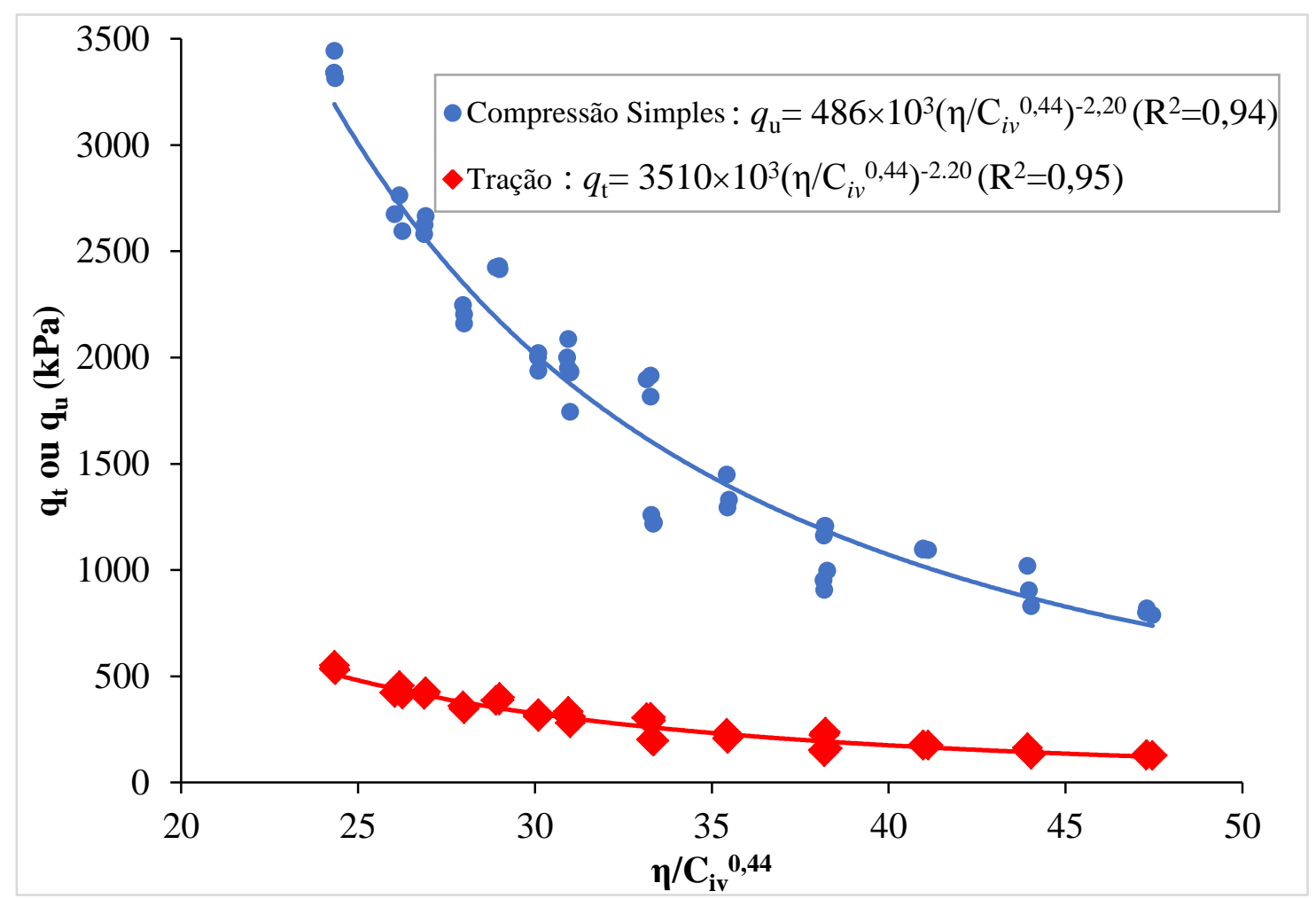

Figura 6: Influência do parâmetro porosidade/cimento na resistência à tração e à compressão do silte rosa 


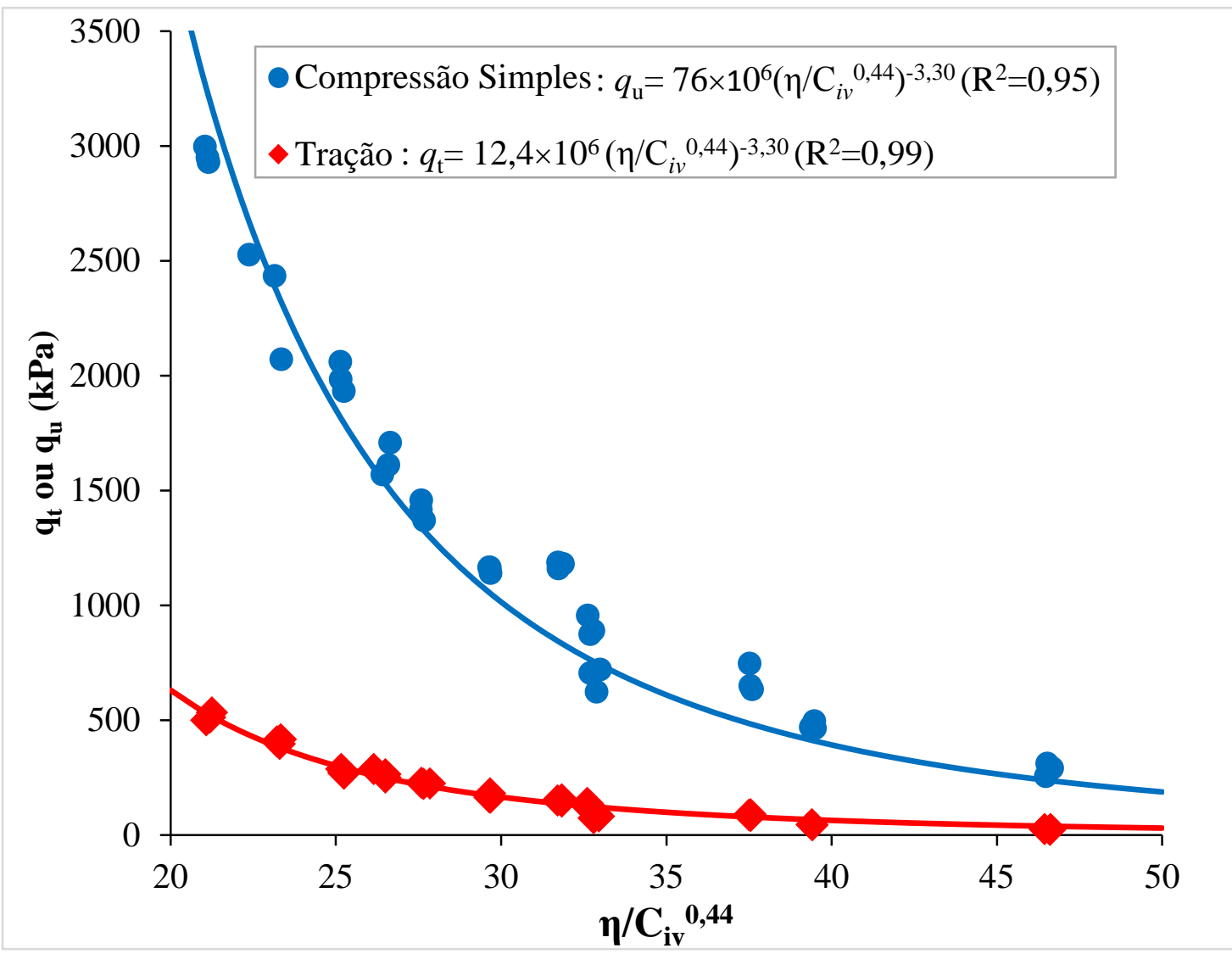

Figura 7: Influência do parâmetro porosidade/cimento na resistência à tração e à compressão do silte amarelo

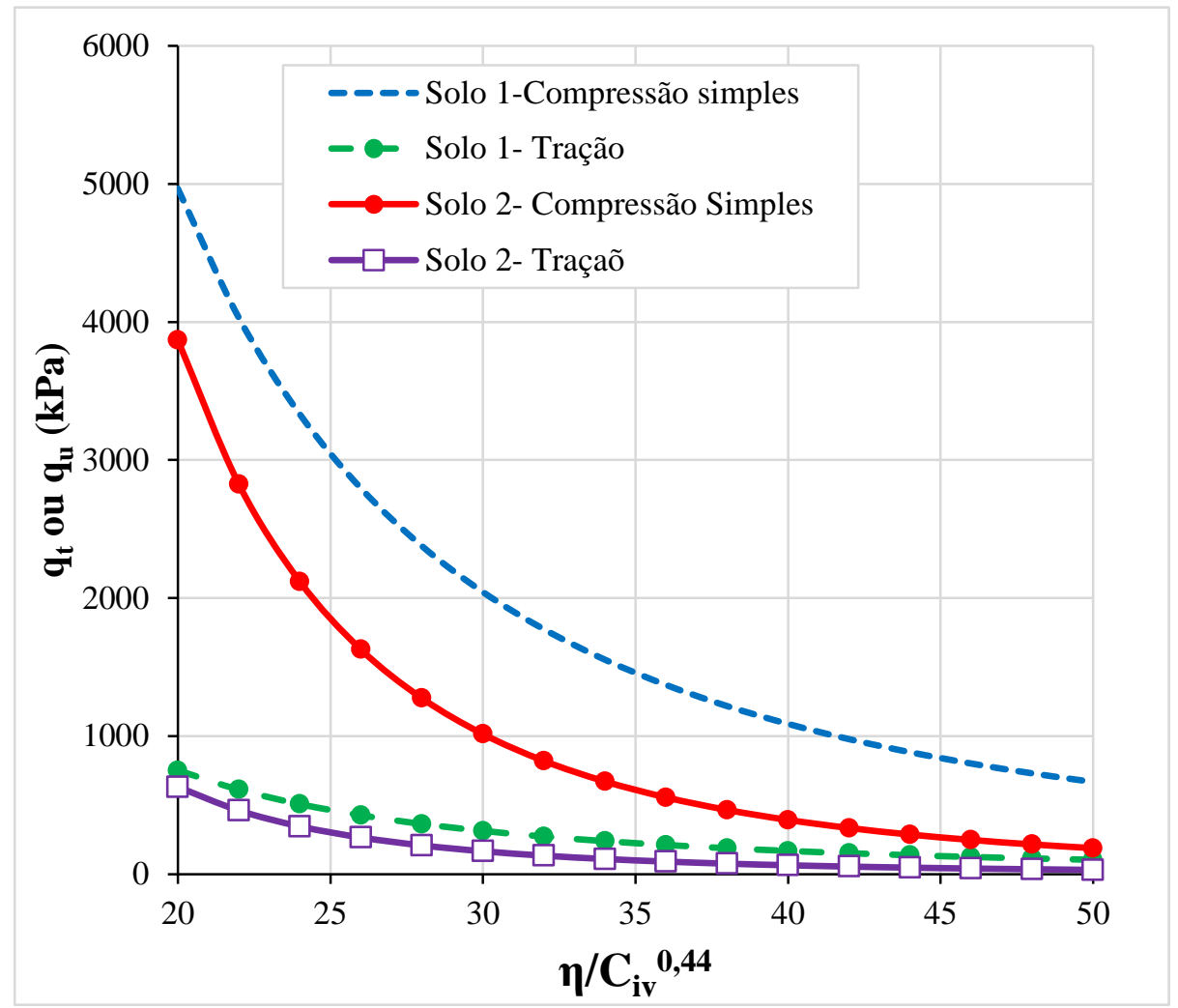

Figura 8: Influência do parâmetro porosidade/cimento na resistência à tração e à compressão dos siltes rosa e amarelo 


\subsection{Relações empíricas entre a compressão simples e à tração}

Uma relação empírica entre a compressão e a tração pode ser calculada em termos do tempo de cura das amostras solo-cimento. Esta relação pode ser chamada de $\xi=\mathrm{q}_{\mathrm{t}} / \mathrm{q}_{\mathrm{u}}$, e é independente da relação $\eta /\left(\mathrm{C}_{i v}\right)^{0,44}$. Desta maneira, as Equações que descrevem o crescimento de $\mathrm{q}_{\mathrm{u}}$ e $\mathrm{q}_{\mathrm{t}}$ em função de $\eta /\left(\mathrm{C}_{i v}\right)^{0,44}$ (Ver Figuras 67) podem ser expressas como uma relação direta de $q_{t} / q_{u}$ para cada tipo de solo utilizado. A relação $q_{t} / q_{u}$ assegura uma constante decimal, a qual é calculada nas Equações (4) e (5). As equações que representam o crescimento de $\mathrm{q}_{\mathrm{u}}$ e $\mathrm{q}_{\mathrm{t}}$ (com tendência potencial) para cada tipo de solo. De forma geral, $\xi$ obtém valores entre 0,14 e 0,16 (variação de $3 \%$ ). Assim, $\mathrm{q}_{\mathrm{t}}$ demonstra ser uma porcentagem de 14 e $16 \%$ do valor de $\mathrm{q}_{\mathrm{u}}$ para $\mathrm{o}$ silte rosa e o silte amarelo, respectivamente.

$\frac{q_{t}}{q_{u}}=\frac{486 \times 10^{3}\left[\frac{\eta}{\left(C_{i v}\right)^{0,44}}\right]^{-2,20}}{3510 \times 10^{3}\left[\frac{\eta}{\left(C_{i v}\right)^{0,44}}\right]^{-2,20}}=0,14$

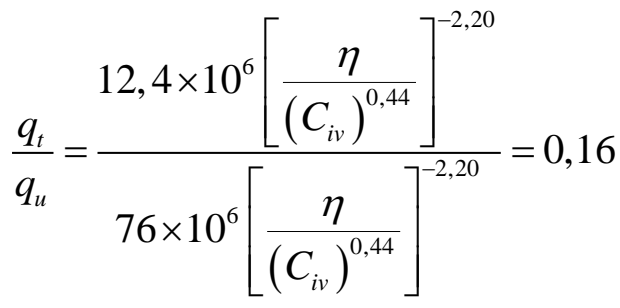

Segundo DIAMBRA et al. [16], para solos arenosos cimentados artificialmente, a existência de uma relação entre as resistências à tração/compressão $\left(\mathrm{q}_{t} / \mathrm{q}_{\mathrm{u}}\right)$ é independente do tempo de cura e está governada, principalmente, pela relação à tração (ou propriedades de fricção) do cimento. Autores como CONSOLI et al. [5] calcularam uma relação $\mathrm{q}_{\mathrm{t}} / \mathrm{q}_{\mathrm{u}}$ de 0,13 para misturas de solos finos compactos com cimento Portland usando teores de umidade de moldagem de 17, 20 e $23 \%$ e pesos específicos secos de moldagem entre 14 e 16 $\mathrm{kN} / \mathrm{m}^{3}$. Logo, FESTUGATO et al. [15] fizeram misturas de um solo arenoso com cimento e fibras de polipropileno; para o solo sem fibras calcularam um valor para $\xi$ de 0,10 e para o solo reforçado com fibras encontraram um valor de $\xi=0,15$ usando uma relação de $\eta /\left(\mathrm{C}_{i v}\right)^{0,28}$. Outros autores como ANGGRAINI et al. [39] determinaram uma relação direta de $\xi=0,16$ para um solo mole reforçado com fibras de coco e tratado com cal. Para CORREIA et al. [40] existe uma diminuição na relação $\mathrm{q}_{\mathrm{t}} / \mathrm{q}_{\mathrm{u}}(\mathrm{de} 0,20$ para 0,24$)$ com o incremento das quantidades de cimento-slag-fibra em uma mesma mistura. MUNTOHAR et al. [41] estudaram a relação $\mathrm{q}_{\mathrm{t}} / \mathrm{q}_{\mathrm{u}}$ para um solo estabilizado com cal e reforçado com fibras. A adição de fibras ao solo estabilizado aumentou ligeiramente o valor de $\xi$ de cerca de 0,11 para 0,13 , aumentando o teor de fibra de 0,1 para $1,2 \%$. Finalmente, BALDOVINO et al. [42]-[43] calcularam valores de $\xi=0,14-0,17$ para misturas solo da FG-cimento. Assim, nota-se que a relação de resistência $\xi$ para solos cimentados/reforçados varia em média entre 10 e $20 \%$. Por conseguinte, as relações empíricas de $q_{t}$ e $q_{u}$ reportadas neste estudo estão entre essas faixas.

\section{CONCLUSÕES}

De acordo com o programa experimental e as análises dos resultados, as seguintes conclusões podem ser estabelecidas:

-Todos os resultados de resistência à compressão simples e tração por compressão diametral das misturas silte amarelo/rosa-cimento foram adequadas à relação porosidade/cimento $\left(\eta / C_{i v}\right)$. Para proporcionar uma variação compatível entre $\mathrm{q}_{\mathrm{t}}$ e $\mathrm{q}_{\mathrm{u}}$ com a relação $\eta / \mathrm{C}_{\mathrm{iv}}$, os valores de $1 / \mathrm{C}_{\mathrm{iv}}$ foram ajustados a um expoente de 0,44 . Assim, a influência da porosidade $(\eta)$ de cada mistura exerceram maior atuação nas resistências $\mathrm{q}_{\mathrm{u}} \mathrm{e}$ $\mathrm{q}_{\mathrm{t}}$ do que $\mathrm{C}_{\mathrm{iv}}$, de tal forma que um aumento em $\eta$ precisa de um incremento proporcionalmente maior no teor de cimento, a fim de compensar o aumento dos vazios devido à falta de compactação e manter a resistência 
constante.

-Em média, 5\% de adição de cimento em peso compactando acima de um peso específico seco de $14 \mathrm{kN} / \mathrm{m}^{3}$ possibilita que ambos solos sejam potencialmente adequados para construção de bases e sub-bases de acordo aos requerimentos do DNIT 143 e do TXDOT.

-Em termos de acréscimos de resistência, o solo rosa obteve maiores resistências à tração e à compressão simples que o solo amarelo. Assim, com a relação $\eta / C_{i v}$ foi possível estabelecer uma relação entre $q_{u}$ e $q_{t}$ $\left(\xi=\mathrm{q}_{\mathrm{t}} / \mathrm{q}_{\mathrm{u}}\right)$ para os dois siltes, sendo essa relação de $\xi=0,14$ e $\xi=0,16$ para o silte rosa e silte amarelo, respectivamente.

\section{AGRADECIMENTOS}

Os autores agradecem o apoio da CAPES, CNPq e Fundação Araucária do Paraná no Brasil. Os autores querem agradecer também os revisores anônimos pelas correções e sugestões que melhoraram o artigo.

\section{BIBLIOGRAFIA}

[1] BUNAWAN, A.R., MOMENI, E., ARMAGHANI, D.J., et al., "Experimental and intelligent techniques to estimate bearing capacity of cohesive soft soils reinforced with soil-cement columns", Measurement, v. 124, pp. 529-538, Ago. 2018.

[2] JIN, L., SONG, W., SHU, X., et al., "Use of water reducer to enhance the mechanical and durability properties of cement-treated soil”, Constr Build Mater, v. 159, pp. 690-694, Jan. 2018.

[3] FAN, J., WANG, D., QIAN, D. "Soil-cement mixture properties and design considerations for reinforced excavation”, J Rock Mech Geotech Eng, v. 10, n. 4, pp. 791-797, Ago. 2018.

[4] MOSA, A.M., TAHER, A.H., AL-JABERI, L.A. "Improvement of poor subgrade soils using cement kiln dust", Case Stud Constr Mater, v. 7, pp. 138-143, Dez 2017.

[5] CONSOLI, N.C., QUIÑÓNEZ, R.A., GONZÁLEZ, L.E., et al., "Influence of Molding Moisture Content and Porosity/Cement Index on Stiffness, Strength, and Failure Envelopes of Artificially Cemented FineGrained Soils", J Mater Civ Eng, v. 29, n. 5, pp. 04016277, Maio 2017.

[6] RIOS, S., VIANA DA FONSECA, A., BAUDET, B.A. "Effect of the Porosity/Cement Ratio on the Compression of Cemented Soil”, J Geotech Geoenvironmental Eng, v. 138, n. 11, pp. 1422-1426, Nov. 2012.

[7] FAN, J., WANG, D., QIAN, D. "Soil-cement mixture properties and design considerations for reinforced excavation", J Rock Mech Geotech Eng, v. 10, n. 4, pp. 791-797, Ago. 2018.

[8] ONYELOWE, K., BUI VAN, D. "Structural analysis of consolidation settlement behaviour of soil treated with alternative cementing materials for foundation purposes", Environ Technol Innov, v. 11, pp. 125-141, Ago. 2018.

[9] CHOOBBASTI, A.J., KUTANAEI, S.S. "Microstructure characteristics of cement-stabilized sandy soil using nanosilica”, J Rock Mech Geotech Eng, v. 9, n. 5, pp. 981-988, Out. 2017.

[10] BALDOVINO, J.A., MOREIRA, E.B., TEIXEIRA, W., et al., "Effects of lime addition on geotechnical properties of sedimentary soil in Curitiba, Brazil", J Rock Mech Geotech Eng, v. 10, n. 1, pp. 188-194, Fev. 2018.

[11] SALAMUNI, E., EBERT, H.D., SILVA BORGES, M., et al., "Tectonics and sedimentation in the Curitiba Basin, south of Brazil”, J South Am Earth Sci, v. 15, n. 8, pp. 901-910, Mar 2003.

[12] BALDOVINO, J.A., MOREIRA, E.B., IZZO RL., et al., "Empirical Relationships with Unconfined Compressive Strength and Split Tensile Strength for the Long Term of a Lime-Treated Silty Soil", J Mater Civ Eng, v. 30, n. 8, pp. 06018008, Ago. 2018.

[13] CONSOLI, N.C., FOPPA, D., FESTUGATO, L., et al., "Key Parameters for Strength Control of Artificially Cemented Soils", J Geotech Geoenvironmental Eng, v. 133, n. 2, pp. 197-205, Fev. 2007.

[14] CONSOLI, N.C., PRIETTO, P.D.M., DA SILVA LOPES, L., et al., "Control factors for the long term compressive strength of lime treated sandy clay soil”, Transp Geotech, v. 1, n. 3, pp. 129-136, Set. 2014.

[15] FESTUGATO, L., MENGER, E., BENEZRA, F., et al., "Fibre-reinforced cemented soils compressive and tensile strength assessment as a function of filament length", Geotext Geomembranes, v. 45, n. 1, pp. 7782, Fev. 2017.

[16] DIAMBRA, A., FESTUGATO, L., IBRAIM, E., et al., "Modelling tensile/compressive strength ratio of artificially cemented clean sand", Soils Found, v. 58, n. 1, pp. 199-211, Fev. 2018. 
[17] KARIM, M.E., ALAM, M.J., HOQUE, M.S. "Effect of salinity of water in lime-fly ash treated sand", Int J Geo-Engineering, v. 8, n. 1, pp. 15, 2017.

[18] ASSOCIAÇÃO BRASILEIRA DE NORMAS TÉCNICAS, NBR 7181: Análise Granulometrica, Rio de Janeiro, 2016.

[19] ASSOCIAÇÃO BRASILEIRA DE NORMAS TÉCNICAS, NBR 7180: Solo — Determinação do limite de plasticidade, Rio de Janeiro, 2016.

[20] ASSOCIAÇÃO BRASILEIRA DE NORMAS TÉCNICAS, NBR 6459: Solo - Determinação do limite de liquidez, Rio de Janeiro, 2016.

[21] AMERICAN SOCIETY FOR TESTING AND MATERIALS, ASTM D 854 - 14: Standard Test Methods for Specific Gravity of Soil Solids by Water Pycnometer 1, West Conshohocken, Pa 2014.

[22] ASSOCIAÇÃO BRASILEIRA DE NORMAS TÉCNICAS, NBR 16605-17: Cimento Portland e outros materiais em pó - Determinação da massa específica, Rio de Janeiro, 2017.

[23] ASSOCIAÇÃO BRASILEIRA DE NORMAS TÉCNICAS, NBR 7182: Solo - Ensaio de Compactação, Rio de Janeiro, 2016.

[24] AMERICAN SOCIETY FOR TESTING AND MATERIALS, ASTM C150: Standard Specification for Portland Cement, West Conshohocken, Pa, 2019.

[25] ASSOCIAÇÃO BRASILEIRA DE NORMAS TÉCNICAS, NBR 16697: Cimento Portland- Requisitos, Rio de Janeiro, 2018.

[26] SKEMPTON, A.W. “The Colloidal "Activity” of Clays”, In: 3rd Int. Conf. Soil Mech., v.1, pp. 57-61, 1953.

[27] BALDOVINO, J.A., MOREIRA, E.B., CARAZZAI, É., et al., "Equations controlling the strength of sedimentary silty soil-cement blends: influence of voids/cement ratio and types of cement", Int J Geotech Eng, v. Online, pp. 1-14, 2019.

[28] ABCP- ASSOCIAÇÃO BRASILEIRA DE CIMENTO PORTLAND. "Dosagem das misturas de solocimento. Normas de dosagem e métodos de ensaios (ET 35)", Assos Bras Cim Portl, v.1, pp. 1-57, 2004.

[29] CONSOLI, N.C., QUIÑONEZ, R.A., GONZÁLEZ, L.E., et al., "Influence of Molding Moisture Content and Porosity / Cement Index on Stiffness , Strength , and Failure Envelopes of Artificially Cemented Fine-Grained Soils", J Mater Civ Eng, v. 29, n. 5, pp. 04016277, Maio 2017.

[30] CONSOLI, N.C., MARQUES, S.F.V., FLOSS, M.F., et al., "Broad-spectrum empirical correlation determining tensile and compressive strength of cement-bonded clean granular soils", J Mater Civ Eng, v. 29, n. 6, pp. 06017004, Jun 2017.

[31] ASSOCIAÇÃO BRASILEIRA DE NORMAS TÉCNICAS, NBR 5739: Concreto - Ensaios de Compressão de Corpos de Prova Cilíndricos, Rio Janeiro, 2007.

[32] ASSOCIAÇÃO BRASILEIRA DE NORMAS TÉCNICAS, NBR 7222: Concreto e argamassa - Determinação da resistência à tração por compressão diametral de corpos de prova cilíndricos, Rio de Janeiro, 2011.

[33] PUPPALA, A.J. "Advances in ground modification with chemical additives: From theory to practice", Transp Geotech, v. 9, pp. 123-138, Dez. 2016.

[34] NATIONAL DEPARTMENT OF TRANSPORT INFRASTRUCTURE. DNIT 143: Pavement Soilcement base- Service specification. DNIT, 2010.

[35] HENZINGER, C., SCHUHMACHER, S.A., FESTUGATO, L. "Applicability of the Porosity/Binder Index to Nonhomogeneous Mixtures of Fine-Grained Soil with Lignite Fly Ash", J Mater Civ Eng, v. 30, n. 9, pp. 06018013, Set. 2018.

[36] LI, L., AUBERTIN, M. "A general relationship between porosity and uniaxial strength of engineering materials", Can J Civ Eng, v. 30, n. 4, pp. 644-658, Ago. 2003.

[37] CONSOLI, N.C., DA SILVA LOPES, L., HEINECK, K.S. "Key Parameters for the Strength Control of Lime Stabilized Soils", J Mater Civ Eng, v. 21, n. 5, pp. 210-216, Maio 2009.

[38] RIOS, S., VIANA DA FONSECA, A., CONSOLI, N.C, et al., "Influence of grain size and mineralogy on the porosity/cement ratio", Géotechnique Lett, v. 3, n. 3, pp. 130-136, Set. 2013.

[39] ANGGRAINI, V., ASADI, A., HUAT, B.B.K., et al., "Effects of coir fibers on tensile and compressive strength of lime treated soft soil", Measurement, v. 59, pp. 372-381, Jan. 2015.

[40] CORREIA, A.A.S., VENDA OLIVEIRA, P.J., CUSTÓDIO, D.G. "Effect of polypropylene fibres on 
the compressive and tensile strength of a soft soil, artificially stabilised with binders", Geotext Geomembranes, v. 43, n. 2, pp. 97-106, Abr. 2015.

[41] MUNTOHAR, A.S., WIDIANTI, A., HARTONO, E., et al., "Engineering Properties of Silty Soil Stabilized with Lime and Rice Husk Ash and Reinforced with Waste Plastic Fiber", J Mater Civ Eng, v. 25, n. 9, p. 1260-1270, Set. 2013.

[42] BALDOVINO, J.A., IZZO, R.L., FELTRIM, F., et al., "Experimental Study on Guabirotuba's Soil Stabilization Using Extreme Molding Conditions", Geotechnical and Geological Engineering, v. Online, pp. 119, 2020.

[43] BALDOVINO, J.A., IZZO, R.L., FELTRIM, F., et al., "Equations controlling tensile and compressive strength ratio of sedimentary soil-cement mixtures under optimal compaction conditions", J Mater Civ Eng, v. 32, n. 1, pp. 04019320, Jan. 2020.

\section{ORCID}

Jair de Jesús Arrieta Baldovino

Ronaldo Luis dos Santos Izzo

Wagner Teixeira

Mirian Dayane Pereira https://orcid.org/0000-0001-7740-1679

https://orcid.org/0000-0002-6290-1520

https://orcid.org/0000-0001-8409-9703

https://orcid.org/0000-0002-3228-7072 